\title{
Honey bee (Apis mellifera) colony strength and its effects on pollination and yield in highbush blueberries (Vaccinium corymbosum)
}

\author{
Kennedy Judith Grant ${ }^{1}$, Lisa DeVetter ${ }^{2}$, Andony Melathopoulos ${ }^{\text {Corresp. } 3}$ \\ 1 Department of Integrative Biology, Oregon State University, Corvallis, Oregon, United States \\ 2 Department of Horticulture, Washington State University, Mount Vernon, Washington, United States \\ 3 Department of Horticulture, Oregon State University, Corvallis, Oregon, United States \\ Corresponding Author: Andony Melathopoulos \\ Email address: Andony.Melathopoulos@oregonstate.edu
}

Many pollination studies with honey bees have examined the effect of colony density on crop yield and yet overlook the effect of variation in the population size of these colonies. High colony density in northern highbush blueberry has been met with concerns from beekeepers who feel higher densities will intensify outbreaks of European foulbrood (EFB, Melissococcus plutonius, Truper and dé Clari ), a honey bee brood disease. The purpose of this study was to confirm the prevalence of EFB in colonies pollinating blueberries and to determine whether field-level variation in the population of adult workers in colonies explained variation in blueberry fruit set and/or yield. We addressed these objectives over the course of two production seasons at 13 commercial blueberry fields in Oregon, USA, stocked with identical densities of 10 colonies/ha. We confirmed that all colonies had negligible symptoms of EFB at the start of blueberry pollination, but $53 \%$ of colonies in 2019 and $41 \%$ in 2020 had symptoms immediately following the pollination season. We also validated a method for rapidly assessing adult honey bee colony populations, namely by counting the rate of foragers returning to colonies, and it was found to be strongly correlated to true internal adult bee population independent of year and ambient temperature at the time of evaluation. Using returning forager counts, we determined there was considerable variation in the average population of colonies at each field, ranging from an estimated 10,300 to 30,700 adult worker bees per colony. While average colony strength did not predict variation in fruit set, it was related to variation in yield, independent of year. Our linear model of flight count (as a proxy for colony strength) predicts estimated yield increases of up to $25,000 \mathrm{~kg} / \mathrm{ha}$ of blueberries could be achieved by colonies stronger than the recommended six frame minimum, suggesting that higher pollination benefits could be achieved without increasing hive density if stronger colonies are promoted.

PeerJ reviewing PDF | (2021:02:57974:1:1:NEW 20 Apr 2021) 
2 Honey bee (Apis mellifera) colony strength and its effects on 3 pollination and yield in highbush blueberries (Vaccinium corymbosum)

\author{
Kennedy Judith Grant ${ }^{1}$, Lisa Wasko DeVetter ${ }^{2}$, and Andony Melathopoulos ${ }^{3}$ \\ ${ }^{1}$ Department of Integrative Biology, Oregon State University, Corvallis, Oregon, 97331, USA \\ ${ }^{2}$ Department of Horticulture, Washington State University Northwestern Washington Research \\ and Extension Center, Mount Vernon, WA, 98273, USA \\ ${ }^{3}$ Department of Horticulture, Oregon State University, Corvallis, Oregon, 97331, USA \\ Corresponding Author: \\ Andony Melathopoulos ${ }^{3}$ \\ Department of Horticulture, Oregon State University, Corvallis, Oregon, 97331, USA \\ Email address: Andony.Melathopoulos@oregonstate.edu
}

\begin{abstract}
Many pollination studies with honey bees have examined the effect of colony density on crop yield and yet overlook the effect of variation in the population size of these colonies. High colony density in northern highbush blueberry has been met with concerns from beekeepers who feel higher densities will intensify outbreaks of European foulbrood (EFB, Melissococcus plutonius, Truper and dé Clari), a honey bee brood disease. The purpose of this study was to confirm the prevalence of EFB in colonies pollinating blueberries and to determine whether field-level variation in the population of adult workers in colonies explained variation in blueberry fruit set and/or yield. We addressed these objectives over the course of two production seasons at 13 commercial blueberry fields in Oregon, USA, stocked with identical densities of 10 colonies/ha. We confirmed that all colonies had negligible symptoms of EFB at the start of blueberry pollination, but 53\% of colonies in 2019 and $41 \%$ in 2020 had symptoms immediately following the pollination season. We also validated a method for rapidly assessing adult honey bee colony populations, namely by counting the rate of foragers returning to colonies, and it was found to be strongly correlated to true internal adult bee population independent of year and ambient temperature at the time of evaluation. Using returning forager counts, we determined there was considerable variation in the average population of colonies at each field, ranging from an estimated 10,300 to 30,700 adult worker bees per colony. While average colony strength did not predict variation in fruit set, it was related to variation in yield, independent of year. Our linear model of flight count (as a proxy for colony strength) predicts estimated yield increases of up to $25,000 \mathrm{~kg} / \mathrm{ha}$ of blueberries could be achieved by colonies stronger than the recommended six frame minimum, suggesting that higher pollination benefits could be achieved without increasing hive density if stronger colonies are promoted.
\end{abstract}


45

46

47

48

49

50

51

52

53

54

55

56

57

58

59

60

61

62

63

64

65

66

67

68

69

70

71

72

73

74

75

76

77

78

79

80

81

82

83

84

85

86

87

88

89

90

\section{Introduction}

Northern highbush blueberry production in the Pacific Northwest (PNW; Oregon and Washington) has been rapidly expanding with a $21 \%$ increase in utilized production of blueberries from 2018 to 2019 (USDA NASS 2019). In Oregon, 70.5 million kilograms of blueberries were produced alone in 2019, valued at around $\$ 134$ million and representing $23 \%$ of total national production (USDA NASS 2020). Although highbush blueberry cultivars are considered self-fertile, their morphology makes passive self-pollination difficult (Kloet 1988), resulting in higher fruit set and yields following insect visitation (Delaplane \& Mayer 2000; Free 1993; McGregor 1976). Moreover, bee pollination enables cross-pollination among cultivars, which has been shown to result in larger fruit, better fruit quality, and earlier ripening of berries (MacKenzie 1997; Brewer \& Dobson 1969; Brewer et al. 1969). Most of this pollination is the result of visitation by foragers of the managed European honey bee, particularly on large, commercial-scale blueberry production (Isaacs \& Kirk 2010; Gibbs et al. 2016; Hoffman et al. 2018), even though a number of wild bee species have been shown to be more efficient pollinators of highbush blueberry at the individual bee level (Javorek et al. 2002).

The minimum population size or "strength" of colonies delivered by beekeepers for crop pollination is frequently specified in state Extension service recommendations (Sagili \& Burgett 2011; NJ Commercial Vegetable Production Recommendations 2015; Canadian Honey Council n.d.; Delaplane \& Mayer 2000; Frazier 2016; Mayer \& Burgett 1993). Adult colony population is also regarded as an important factor by growers in judging the quality of rented colonies. In the high-value California almond [Prunus dulcis Miller (DA Webb)] pollination market, growers who specify minimum colony strength in their contracts with beekeepers were found to pay higher rates for colonies compared to growers who do not specify colony strength (Goodrich \& Goodhue 2020). Yet, despite the considerable attention on colony strength, there have been few studies to date examining the connection between colony strength and crop yields (although see Geslin et al. 2017).

In Oregon and Washington, the minimum colony strength for blueberry pollination is defined as having six Langstroth-sized frames covered with adult bees (Sagili \& Burgett 2011). However, blueberry growers often lack the tools necessary to assess internal frame counts and therefore adult colony populations. Recognizing this limitation, the Extension Service in these states recommends an alternative, non-invasive measure that can be performed by growers, whereby the grower estimates the rate of returning foragers to a colony (Sagili \& Burgett 2011). A colony that is minimally sufficient has more than 100 returning bees per minute at air temperatures $18^{\circ} \mathrm{C}$ and above and with winds less than $15 \mathrm{~km} / \mathrm{hr}$. Another rapid assessment method developed for California almond pollination, termed "cluster counts", involves separating colony brood chambers and counting the number of spaces between frames covered by bees (Nasr et al. 1990); However, this method is more difficult for growers to perform without the assistance of a beekeeper compared to assessing the rate of returning foragers. Notably, while cluster counts have been shown to predict adult colony populations (Nasr et al. 1990; Chabert et al. 2021), there are no studies validating the non-invasive method of enumerating the rate of returning foragers method. Furthermore, the returning foragers method is specific to air temperatures that are frequently not achieved during the cool blueberry bloom period in the PNW (DeVetter et al. 2016), which makes the validity of this approach uncertain. 
91

92

93

94

95

96

97

98

99

100

101

102

103

104

105

106

107

108

109

110

111

112

113

114

115

116

117

118

119

120

121

122

123

124

125

126

127

128

129

130

131

132

133

134

135

136
In contrast to the absence of studies assessing the effect of colony population on yield, there have been a number of studies examining the effect of manipulating colony density, also known as stocking rate (Rollin \& Garibaldi 2019). Blueberry growers, on average, use anywhere from 6.212.3 colonies per ha, which is considered to be sufficient for pollination services (Brewer et al. 1969; Gibbs et al. 2016; Isaacs \& Kirk 2010). Higher than recommended stocking rates (10 colonies/ha) have also been shown to promote blueberry yield by DeVetter et al. (2016), although notably, none of their fields were stocked with colonies that had an average minimum of 100 returning foragers per minute. However, average air temperatures in this study were largely below the $18^{\circ} \mathrm{C}$ threshold described by Sagili \& Burgett (2011). Without validation of the returning forager method, it is unclear whether the method underestimates adult populations in colonies, or if colonies delivered for pollination in their study were consistently below grade. The latter possibility raises the question of whether yield could alternatively be increased at a lower stocking rate with stronger colonies.

Increasing stocking rate in blueberries has been met with resistance from some beekeepers due to coincidental reports of a honey bee brood disease seemingly associated with blueberry pollination. European foulbrood (EFB) has been correlated with the pollination of Vaccinium spp. across the US spanning back to the 1980 s, although there are no studies documenting this phenomenon in the large blueberry production regions of the PNW (Martin et al. 2019; Arrington \& DeVetter 2018; Gibbs et al. 2016; Wardell 1983; Lehnert \& Shimanuki 1980; Waite et al. 2003). Oregon beekeepers have reported to one of the authors (A. Melathopoulos) that they are concerned higher stocking rates will result in higher transmission rates of the disease's causative bacterial pathogen (Melissococcus plutonius, Truper and dé Clari), and lead to more inter-colony competition, resulting in elevated stress that would render colonies even more susceptible to the disease.

The preliminary goal of this study was to determine whether there is an alternative approach to increasing blueberry yield that benefits both beekeepers and growers; not by adding additional colonies per hectare, but by supplying stronger, higher-quality colonies. An additional purpose was to assess whether variation in blueberry yield could be explained by variation in the strength of colonies used for pollination. To address these, we examined the correlation between the internal adult colony population and the rate at which foraging bees returned to the colony to determine if the relationship was strong enough to evaluate apiaries in our study and to provide growers with a reliable assessment tool. Finally, colony brood diseases were evaluated and monitored to verify beekeepers' experiences with increased brood diseases, particularly EFB, during blueberry pollination. For this last objective, our goal was to document the increase in brood diseases, rather than determine the causes for the increase.

\section{Materials \& Methods}

Study location. The survey was performed on eight different commercial blueberry operations in 2019 and 2020, located in the Willamette Valley of western Oregon. A single field of the cultivar 'Duke' was selected from each operation, although in one operation two 'Duke' fields were selected and for four operations a field of 'Liberty' was also included. In total, the study included 9 'Duke' and 4 'Liberty' fields. To maintain independence, all fields were distanced a minimum

PeerJ reviewing PDF | (2021:02:57974:1:1:NEW 20 Apr 2021) 
137 of two kilometers from one another. All field sites were stocked at 10 colonies per hectare, 138 according to guidelines outlined by Oregon State University Extension (Sagili \& Burgett 2011).

139 The blueberry fields in this study were pollinated by a total of five different commercial

140 beekeepers.

141

142

143

144

145

146

147

148

149

150

151

152

153

154

155

156

157

158

159

160

161

162

163

164

165

166

167

168

169

170

171

172

173

174

175

176

177

178

179

180

181

182
Colony strength. Strength was assessed in 2019 ( $n=166$ colonies) and 2020 ( $n=161$ colonies) by randomly selecting colonies and assessing flight entrance counts (see below). The selected colonies constituted approximately $25 \%$ of all colonies pollinating each blueberry field. The counts were conducted once per field at early $(\sim 20 \%$ bloom $)$ or peak blueberry bloom. The flight entrance count method of assessing colony strength was validated on a subset of colonies $(n=48)$ at four different fields in 2019 by comparing flight counts to two additional methods of assessing honey bee colony populations, namely frame-by-frame counts (Liebefeld method) and cluster counts (described below). These multiple assessments were repeated at three fields in 2020 $(n=36)$, using the same beekeepers and fields as used in 2019. Frame-by-frame and cluster counts were conducted 2-3 times per season, throughout early (20-27 April), middle (3-11 May), and late (15-25 May) bloom. In 2019, each colony was assessed at least twice, first within a week of being placed in fields (early bloom) and second a week before being removed from fields when pollination was complete (late bloom; $<10 \%$ bloom remaining), while three fields had an additional assessment mid-season in an effort to increase the sample size for the entrance count correlations. In 2020, colony assessments were again conducted twice, once in early and once in late bloom, while one additional beekeeper pollinating blueberries was assessed for colony strength parameters once during mid-bloom. Notably, this additional beekeeper was not located in a field used for any measures of flower visitation, fruit set or yield (see section below). Colony entrance count assessments were conducted within 48 hours of the same colonies being assessed for cluster counts or frame-by-frame assessments.

The first method we used for assessing colony population is known as the Liebefeld method, which involves assessing each Langstroth-sized frame in the colony for coverage with adult bees and sealed brood. This labor-intensive method represents the current standard for assessing honey bee colony populations (Dainat et al. 2020). We compared populations assessed using the Liebefeld method to two, labor-saving methods. Cluster counts were assessed as described by Nasr et al. (1990), which involved counting the number of frame-spaces occupied by bees from the tops and bottoms of frames without removing frames from the box. Cluster count assessments were performed immediately prior to assessments using the Liebefeld method and when temperatures were below $15^{\circ} \mathrm{C}$ and before foragers departed at the beginning of the day. The second alternative method was the flight entrance count method described by Sagili and Burgett (2011), and involved counting the number of returning forager bees returning to colonies over a 1-minute period between 10:00 AM to 4:00 PM when temperatures were above $12{ }^{\circ} \mathrm{C}$, there was no precipitation, and winds were less than $15 \mathrm{~km} / \mathrm{hr}$. Although Sagili and Burgett's (2011) recommendations specify $\geq 18^{\circ} \mathrm{C}$ in their assessments, temperatures at or above this threshold were seldom achieved and an adjusted threshold of $12{ }^{\circ} \mathrm{C}$ was recorded for this study, which reflects natural field conditions (Tuell \& Isaacs 2010). Counts were made from video recordings of flight activity of all colony entrances. Videos were slowed down post-production, and the number of honey bees that completely entered the colony within the time interval was manually counted. 
183 Colony diseases. All colonies evaluated by frame-by-frame population assessments (see above) 184 were also evaluated for the following honey bee brood diseases: EFB (M. plutonius), American 185 foulbrood (caused by Paenibacillus larvae bacteria), chalkbrood (caused by Ascosphaera apis 186 fungus), and sacbrood (virus). Assessments were conducted at the onset of pollination and 187 immediately before they were moved out of the fields in 2019 and 2020. Field diagnosis of the 188 brood diseases was performed by an experienced honey bee pathologist (A. Melathopoulos).

189 EFB was confirmed using molecular techniques described by (Wood et al. 2020). Briefly, 190 whenever EFB was identified in an apiary on a given survey date, a minimum of three EFB191 diseased were collected using a sterile swab, crushed and stored at $-20^{\circ} \mathrm{C}$ after returning to the lab at the end of the day. The samples were shipped frozen to the University of Saskatchewan where they were cultured on KSBHI agar. Any colonies resembling M. plutonius were subcultured on KSBHI and confirmed using gram staining and duplex PCR. Confirmed M. plutonius were further characterized using multi-locus sequence typing (MLST) to detect atypical genetic variants of the disease. The number of diseased larva/pupae per colony was scored using an 3-point ordinal scale adapted from (Spivak \& Reuter 2001) where $0=$ no disease, $1=1-10$ diseased cells per colony, $2=11-50$ diseased cells per colony, $3>51$ diseased cells per colony.

Flower visitation, fruit set, berry weight, and yield. Honey bee visitation measurements outlined in this section were adapted from (Courcelles et al. 2013), with methods following DeVetter et al. (2016). Measurements were conducted on 30 randomly selected blueberry bushes per field in both 2019 and 2020. Bushes were located within 3 randomly selected rows within each field, with 10 bushes randomly selected per row per (10 plants per transect $x 3$ transects per site) (DeVetter et al. 2016). Honey bee and bumble bee (Bombus sp.) visitation were conducted twice (early and peak bloom; $\sim 20$ and $100 \%$ bloom, respectively) and involved counting the total number of legitimate pollination events over a 1 min observation period for each bush for each period (i.e., honey bee foraged within the flower and entered through the corolla rather than nectar robbing). Floral visitation was conducted between 10:00 AM to 4:00 PM when temperatures were at $12{ }^{\circ} \mathrm{C}$ or above and there was no precipitation and less than $15 \mathrm{~km} / \mathrm{hr}$ wind. Fruit set was estimated by counting the total number of flowers and fruit (at the stage when fruit was $\sim 4 \mathrm{~mm}$ in diameter) on four randomly selected flowering clusters per tagged bush. The average number of flower clusters per cane and number of canes per tagged bush were also recorded. Immediately prior to commercial harvest ( $75 \%$ fruit had turned blue) 10 berries were randomly picked per bush (i.e., 300 berries per field) and weighed in order to determine the average berry weight. Estimated yield per field was calculated with the following formula:

$$
\frac{\text { yield }}{\text { acre }}(\text { lbs })=\text { avg berry weight } \times \text { avg } \frac{\text { berries }}{\text { cluster }} \times \text { avg } \frac{\text { clusters }}{\text { cane }} \times \text { avg } \frac{\text { canes }}{\text { bush }} \times \frac{\text { bushes }^{*}}{\text { acre }}
$$

$$
\text { *bushes/acre was provided as an industry standard of } 2000 .
$$

Statistical analysis. Data were analyzed using Program R (R Core Team; R Foundation for Statistical Computing, Vienna, Austria). Differences in the average strength, as well as the severity of EFB from the beginning to the end of blueberry pollination, were compared with twosample Wilcoxon sum rank tests. Hives that only had one assessment were not included in these comparisons. We used Kendall's Tau correlation coefficient to assess whether returning flight 
228

229

230

231

232

233

234

235

236

237

238

239

240

241

242

243

244

245

246

247

248

249

250

251

252

253

254

255

256

257

258

259

260

261

262

263

264

265

266

267

268

269

270

271

272 counts were a comparable colony strength metric alongside cluster counts and could be a reliable indicator of adult bee populations in the field, as assumptions for the Pearson correlation of normal distribution of data were not consistently met for all variables. Kendall's Tau correlation coefficients were also implemented to determine whether there were any significant relationships between this new estimate of colony population (mean return rate of foragers), estimates of pollination activity (mean honey bee flower visits, mean bumble bee flower visits), and fieldlevel yield parameters (mean fruit set, mean flowers per bush, mean berry weight. For the former assessment, any hive that was not assessed using all three measures or whose measurements were taken longer than 48 hours apart were dropped from the final yield correlation analysis. We tested the hypothesis that returning flight counts predict true adult bee populations using least square means linear regression, with year of study as a factor and ambient temperature at the time of the returning forager count as a covariate. We also used least square means linear regression to test the hypothesis that flight counts predicted yield, with year of study and cultivar as factors, confirming the assumptions of the model by quantile plots and scatterplots of residuals versus predicted values.

\section{Results}

Colony quality during blueberry pollination. Colonies did not experience significant growth during the 3-4 weeks of blueberry pollination in 2019 (Fig 1; $W=914.5, d f=42, P=0.93$ ). Moreover, colonies experienced elevated numbers of brood diseases, with $63 \%$ being free of symptoms before pollination and $19 \%$ remaining free of diseases by the end of pollination, with colonies having an average of 1 distinct brood disease. The growth in the incidence of EFB between in-field placement and when they were removed was distinctive in both 2019 and 2020 (Fig 2; $2019-W=495, d f=85, P<0.001 ; 2020-W=219.5, d f=63, P<0.001$ ). Levels of EFB in colonies before pollination were very low in both years, with only a single beginning colony in 2020 showing symptoms at the lowest disease rating (Fig 2b). Molecular analysis of samples of EFB-diseased larvae analyzed by the University of Saskatchewan confirmed that some of the strains found in colonies were of a strain of M. plutonius that is atypical and causes high levels of larval mortality (personal correspondence, Sarah Woods). In 2019, very low levels of both chalkbrood and sacbrood were observed in early and late bloom, with neither having significant increases throughout the season. Sacbrood had a slight increase in severity with colonies having an average rating of 0.1 in early bloom and 0.7 in late bloom, however, the magnitude of this change was not comparable to that which was seen in EFB. In 2020, minor increases in sacbrood prevalence and severity were again observed, while chalkbrood AFB cases were virtually undetectable.

Validation of flight entrance estimates of colony strength. Incoming flight entrance counts (mean 68.86; $\mathrm{SD} \pm 31.94$; range 11-144) were significantly correlated to both the current standard method of assessing adult bee populations using frame-by-frame coverage (Liebefeld method) and cluster counts (Fig 3) $(P<0.001)$. Notably, flight entrance counts were also significantly correlated to colony sealed brood population. Incoming flight entrance counts were significantly related to adult populations estimated using frame-by-frame counts $\left(\mathrm{R}^{2}=0.37, P<0.001\right)$, independent of the year of assessment $(P=0.6)$ or variation in-flight temperature $(P=0.3)$ across a temperature range from $\left.13-23^{\circ} \mathrm{C}\right)(\mathrm{Fig} 4)$. We estimated that for every 13 bees returning to the

PeerJ reviewing PDF | (2021:02:57974:1:1:NEW 20 Apr 2021) 
273 colony per minute, there would be 1 additional full frame of Langstroth frames covered with

274 adult bees.

275

276

277

278

279

280

281

282

283

284

285

286

287

288

289

290

291

292

293

294

295

296

297

298

299

300

301

302

303

304

305

306

307

308

309

310

311

312

313

314

315

316

317

318

Colony quality and yield. Average colony strength per field estimated from flight entrance counts was a better predictor of yield compared to floral visits on bushes in both years, and notably, in 2019 , colony strength was slightly negatively correlated with honey bee flower visits and bumble bee flower visits (Fig 5). Only 2\% of bush visitation surveys in 2019 and 5\% in 2020 recorded one or more bumble bee visits, the highest count from a single visit being 13 in 2019. No other bee taxa were observed visiting flowers during the study. Overall, variation in colony strength and the number of flowers per bush appeared most strongly associated with variation in yield. There was a significant positive fit between the average colony strength and yield in both 2019 and $2020\left(\mathrm{R}^{2}=0.42, \mathrm{P}<0.001\right)$, independent of the year $(P=0.5)$ and blueberry cultivar $(P=0.3)$ (Fig. 6). We estimate that for every 10 bees per minute increase in average colony population, growers would realize a $4450 \mathrm{~kg} / \mathrm{ha}$ increase in blueberry yield, assuming $\sim 2,400$ bees per Langstroth-sized frame (Burgett \& Burikam 1985).

\section{Discussion}

Our study is the first to demonstrate that yield benefits associated with crop pollination are related to returning forager rates as a proxy for the strength of honey bee colonies brought into pollination. We observed a $70,000 \mathrm{~kg} / \mathrm{ha}$ difference in estimated blueberry yield among fields in our study stocked with 10 colonies/ha, and predicted that around $40 \%$ of this variation could be explained by variation in returning foragers as an indicator for honey bee colony strength. By creating a linear model where incoming flight entrance counts predict estimated blueberry yield, we saw a $62.6 \%$ difference in the estimates between colonies at the $25^{\text {th }}$ percentile ( 6.4 adult frames; 42.6 bees per minute) and the $75^{\text {th }}$ percentile ( 10.2 adult frames; 90.3 bees per minute). Moreover, the non-invasive method we used to assess honey bee colony strength (flight entrance counts) should be easy for growers to perform and are correlated with more labor-intensive methods used by growers and crop consultants in other cropping systems. We were able to refine the estimates of adult colony population previously developed by Sagili and Burgett (2011), who estimated that a colony meeting the minimum colony strength pollination standard of 6 frames of adult bees should have 100 returning foragers per minute. These findings suggest the returning forager count for 6 frames of adult bees should be 2.6 times lower than previously reported, or 38 returning foragers per minute, and that air temperature does not influence this relationship. Finally, we confirmed reports from Oregon beekeepers that colonies do not experience significant growth during blueberry pollination and large increases in brood diseases, particularly EFB. Combined our research suggests that growers could realize a substantial yield increase by maintaining 10 colony/ha stocking rates, but selecting beekeepers providing stronger colonies for pollination or adjusting colony density based on colony strength. Furthermore, these results may encourage more blueberry growers to establish contracts with their beekeepers, as frequently done in almond production, to help ensure quality.

It is still unknown to what extent EFB is caused by blueberry pollination, or whether a confounding variable is leading to its association with the blueberry pollination season. Explanations for the EFB phenomenon in blueberries include: a nutritional deficiency with blueberry pollen (Girard et al. 2012), low surrounding floral diversity (Colwell et al. 2017), poor

Peer) reviewing PDF | (2021:02:57974:1:1:NEW 20 Apr 2021) 
319 weather conditions during the pollination period (Tuell \& Isaacs 2010), pesticide use (Wood et 320 al. 2020), and the alkalinity of the pollen itself (Wardell 1983), but so far none have been 321 isolated as the sole or primary determinant. While our study determined the presence and prevalence of EFB in a recommended stocking rate, our approach was descriptive and, as such, unable to test the contention of beekeepers that the disease is more severe at a higher stocking rate. It is quite possible, for example, that the disease increases in early spring independent of stocking rate or whether colonies are placed in blueberries. There remains a need for research that investigates the relationship between colony density and the severity of EFB during blueberry pollination. At minimum, there should be a confirmation of the causal connection of EFB to blueberry, perhaps by comparing disease occurrence among colonies from commercial beekeeping operations that are randomly allocated to blueberry and to another unrelated but coincidentally blooming crops such as pear or sweet cherry.

A key limitation of this study is that while Arrington and DeVetter (2018) randomized the stocking rate to fields, findings in this study are correlational and depended on variation within commercial production systems. Future studies should control for colony strength by randomly assigning strong and weak colonies to different fields. A powerful future experimental design could employ a $2 \times 2$ factorial exploring the interaction between stocking rate and colony strength, providing growers with additional insight into balancing these two factors off when making decisions around how many colonies to stock.

Both this study and Arrington and DeVetter (2018) found that flower visitation did not predict yield like other studies suggest (Isaacs \& Kirk 2010). These results are different from those observed on lowbush blueberry (Aras et al. 1996) and rabbiteye blueberry (Vaccinium ashei var. 'Climax') (Dedej \& Delaplane 2003, Danka et al. 2019) One explanation for this discrepancy is that by performing a single assessment of flower visitation per field in a given day, we failed to fully account for flower visitation, which can have strong diurnal patterns in blueberries (Drummond 2016). In contrast, hive entrance counts remained predictive of yield regardless of annual variation and differences in ambient temperatures. While entrance counts themselves are not labor-intensive to survey, the process of reviewing video footage of colonies took as long as 2-3 minutes per colony to assess, especially at higher returning forager counts where slowmotion video replay was required to achieve an accurate estimate. What is not clear from our research is whether reduced accuracy associated with visually estimating forager return rate would be sufficient to discriminate among broad categories of colony population strength. For example, future research may focus on the capacity of growers and crop consultants to discriminate among colonies in the median, lower, or upper quartile of returning forager counts from our study (i.e., $25^{\text {th }}$ quartile $=42.6$ bees $/$ minute, predicted frame count $=6.4$; median $=62.6$ bees $/$ minute, predicted frame count $=8 ; 75^{\text {th }}$ quartile $=90.3 \mathrm{bees} /$ minute, predicted frame count $=10.2$ ), which corresponded with significant increases in yield. Based on the experience of the author responsible for transcribing the returning forager count videos (K. Grant), it seems likely that a trained grower would be able to differentiate between such broad categories. Artificial intelligent algorithms have also been suggested as an even more efficient and similarly accurate process, but price and availability would limit their range (Reka 2016; Magnier et al. 2018; Kulyukin 2017). 
364 What is also unclear from our study is whether some of the variation in the ability to predict

365 frame counts from colony flight is driven by parameters such as weather conditions from the 366 preceding day (Clarke \& Robert 2018) or colony state parameters such as the amount of pollen 367 and nectar stores in colonies (Dogterom \& Winston 1999). Better predictive models might result 368 from multivariate analyses of factors other than colony population that influence colony forager entrance counts.

Arrington and DeVetter (2018) found that when doubling the stocking rate from 10 colonies/ha to 20 colonies/ha, that there was a $22 \%$ and $40 \%$ increase in estimated yield for each of two years in their study, respectively. Colonies used in their study were also evaluated for strength using the returning forager method and were comparably stronger (117 returning foragers per minute) with no differences between treatments. Our results suggest comparable yield increases achieved while doubling stocking rate from 10 to 20 colonies/ha could be achieved through increasing the average population of bees per field. For example, a field stocked with 10 colonies/ha with an average of 38 returning bees per minute (the six frame minimum, Fig. 6), could achieve a $22 \%$ increase in yield if colonies were strengthened to a point where the return rate was 54 bees per minute. Similarly, placing colonies with flight counts from the $50^{\text {th }}$ percentile of our survey ( 62.6 bees per minute), could lead to a $35 \%$ increase in yield compared to colonies meeting the six frame minimum. Notably, the difference in estimated yield between the field with the weakest colonies in our study (average count of 11 bees per minute) to the strongest (119.3 bees per minute), suggests that the former field could yield a hypothetical $250 \%$ increase if stocked with the strongest instead of the weakest colonies. While other horticultural variables can influence total yield, results from this study suggest that stocking blueberry fields with fewer, stronger colonies should be less expensive than stocking at higher densities assuming colony costs are the same and yields benefits are maintained.

This study draws into question the concept of a minimum strength honey bee colony, as highlighted in numerous crop pollination guides, as our research suggests a linear increase in yield based on colony population. For example, Sagili and Burgett (2011) state that the colonies delivered for blueberry pollination should have a minimum of 6 frames covered with adult bees. This standard is also outlined in the Oregon Administrative Rules (Chapter 603, Section 55-005, filed with the Secretary of State on August 17, 1960, as Administrative Order AD 643). Upon further research, we found that these guidelines have since been repealed (Personal correspondence, Ben Zeiner, Oregon State Archives) and at the time of this publication, there is no legal basis in Oregon regarding minimum colony strength for pollination, although the division title still references the "Oregon Standards of Bee Colony Strength" (OAR 2020). Rather than minimum colony population, our findings suggest the potential to develop a rental pay schedule, whereby growers pay more for the average population of colonies delivered to pollination.

Our findings could potentially provide both blueberry growers and beekeepers with higher economic returns. Blueberry pollination is one of the highest users of honey bee colonies for pollination in the PNW region, using approximately 10,000 colonies (rentals valued at $\$ 528$ thousand dollars in 2016) (Sagili \& Caron 2017). Blueberries are also the most valuable honey bee-pollinated crop in the state, with a value of utilized production estimated at \$134 million in 2019 (USDA NASS 2020). If the average price per pound of blueberries is $\$ 2.20 / \mathrm{kg}$, the 
410 difference in gross returns between fields with populous (ex. eight frames; 62.6 bees per minute; 411 the observed median) versus weak (under six frames, ex. four frames; 12.5 bees per minute) 412 colonies would be $\sim \$ 49,000 /$ ha, according to both Fig. 4 and Fig. 6. Given that colonies for 413 blueberry pollination rent, on average, for $\$ 543 /$ ha, it's possible that blueberry growers who 414 incentivize the delivery of stronger colonies could realize more than $100 \%$ returns on investment 415 for beekeepers delivering premium strength colonies, even when factoring in a modest rental fee 416 increase for those colonies. For beekeepers, if higher pollination benefits can be achieved 417 without increasing hive density, this may also lower their operating costs if it resulted in lower 418 levels of EFB, although it remains unclear if stocking density or blueberry pollination cause the 419 observed increases in EFB. The correlation between colony strength and the rate of return of 420 bees from the field will allow growers to assess colony strength after colonies are delivered and 421 potentially adjust fee schedules based on their estimates of colony strength.

422

423

424

425

426

427

428

429

430

431

432

433

434

435

436

437

438

439

440

441

442

443

444

445

446

447

448 We would like to thank Jason Myer, Tom Peerbolt, and their team at Peerbolt Crop Management

\section{Conclusions}

We hypothesized that target yield could be achieved by increasing the strength (i.e., forager population) of honey bee colonies supplied to blueberry pollination without increasing colony density. We validated and refined existing colony population metrics and extrapolated the relationship between adult frame counts and the rate of returning foragers. We found that average colony strength per blueberry field, estimated using the returning forager counts, predicted yield. We also confirmed that honey bee brood experienced elevated levels of disease, most notably EFB, post-blueberry pollination, although our study was descriptive and unable to attribute the increase in disease to blueberry pollination. Colony strength was found to have a positive influence on estimated blueberry yield, suggesting similar profits to increasing colony density could be achieved. Future directions for research include measuring the effect colony density has on colony strength and EFB severity, economic studies that calculate the cost-benefit trade-offs of supplying stronger colonies for pollination, and identifying whether growers can visually estimate flight counts accurately or whether they require technological assistance.

\section{Acknowledgements}

for their help and cooperation with this study, without which this project would not have been possible. We are also extremely grateful for the beekeepers and growers who agreed to let us evaluate their colonies and fields each year.

\section{References}


455

456

457

458

459

460

461

462

463

464

465

466

467

468

469

470

471

472

473

474

475

476

477

478

479

480

481

482

483

484

485

486

487

488

489

490

491

492

493

494

495

496

497

498

499

500

Aras, P., De Oliveira, D. and Savoie, L., 1996. Effect of a honey bee (Hymenoptera: Apidae) gradient on the pollination and yield of lowbush blueberry. Journal of Economic Entomology, 89(5), pp.1080-1083.

Arrington, M. \& DeVetter, L.W., 2018. Increasing honey bee hive densities promotes pollination and yield components of highbush blueberry in western Washington. HortScience, 53(2), pp.191-194. DOI: 10.21273/HORTSCI12644-17

Brewer, J.W. \& Dobson, R.C., 1969. Seed count and berry size in relation to pollinator level and harvest date for the highbush blueberry, Vaccinium corymbosum. Journal of Economic Entomology, 62(6), pp.1353-1356. DOI: 10.1093/jee/62.6.1353

Brewer, J.W., Dobson, R.C. \& Nelson, J.W., 1969. Effects of increased pollinator levels on production of the highbush blueberry, Vaccinium corymbosum. Journal of Economic Entomology, 62(4), pp.815-818. DOI: 10.1093/jee/62.6.1353

Burgett, M. \& Burikam, I., 1985. Number of honey bees (Hymenoptera: Apidae) occupying a comb: A standard for estimating colony populations. Journal of Economic Entomology, 78, pp. 1154-1156. DOI: 10.1093/jee/78.5/1154

Canadian Honey Council, Managing Bees for Pollination. Canadian Honey Council. Available at: http://honeycouncil.ca/archive/managing_bees_for_pollination.php [Accessed January 3, 2021].

Chabert, S., Requier, F., Chadoeuf, J., Guilbaud, L., Morison, N., \& Vaissière, B.E., 2021. Rapid measurement of the adult worker population size in honey bees. Ecological Indicators, 122(107313). DOI: 10.1016/j.ecolind.2020.107313

Clarke, D. \& Robert, D., 2018. Predictive modelling of honey bee foraging activity using local weather conditions. Apidologie, 49(3), pp.386-396.

Colwell, M.J., Williams, G.R., Evans, R.C., \& Shutler, D., 2017. Honey bee-collected pollen in agro-ecosystems reveals diet diversity, diet quality, and pesticide exposure. Ecology and Evolution, 7(18), pp.7243-7253. DOI: 10.1002/ece3.3178

Courcelles, D.M.M., Button, L. \& Elle, E., 2013. Bee visit rates vary with floral morphology among highbush blueberry cultivars (Vaccinium corymbosum L.). Journal of Applied Entomology, 137(9), pp.693-701. DOI: 10.1111/jen.12059

Dainat, B., Dietemann, V., Imdorf, A., \& Charrière, J. D., 2020. A scientific note on the "Liebefeld Method" to estimate honey bee colony strength: its history, use, and translation. Apidologie. 51, pp.422-427. DOI: 10.1007/s13592-019-00728-2

Danka, R.G., Sampson, B.J. and Villa, J.D., 2019. Association between density of foraging bees and fruit set in commercial fields of rabbiteye blueberries (Ericales: Ericaceae) in Louisiana and Mississippi. Journal of economic entomology, 112(3), pp.1322-1326.

Dedej, S. \& Delaplane, K.S., 2003. Honey bee (Hymenoptera: Apidae) pollination of rabbiteye blueberry Vaccinium ashei var. 'Climax' is pollinator density-dependent. Journal of Economic Entomology, 96(4), pp.1215-1220.

Delaplane, K.S. \& Mayer, D.F., 2000. Crop pollination by bees. Wallingford: CABI.

DeVetter, L.W., Watkinson, S., Sagili, R., \& Lawrence, T., 2016. Honey bee activity in northern highbush blueberry differs across growing regions in Washington State. HortScience : a publication of the American Society for Horticultural Science, 51(10), pp.1228-1232. DOI: 10.21273/HORTSCI10934-16

Dogterom, M.H. \& Winston, M.L., 1999. Pollen storage and foraging by honey bees (Hymenoptera: Apidae) in highbush blueberries (Ericaceae), cultivar Bluecrop. The Canadian Entomologist, 131(6), pp.757-768.

PeerJ reviewing PDF | (2021:02:57974:1:1:NEW 20 Apr 2021) 
501 Drummond, F.A., 2016. Behavior of bees associated with the wild blueberry agro-ecosystem in

502

503

504

505

506

507

508

509

510

511

512

513

514

515

516

517

518

519

520

521

522

523

524

525

526

527

528

529

530

531

532

533

534

535

536

537

538

539

540

541

542

543

544

545

546 the USA. International Journal of Entomology and Nematology. 2(1), pp.027-041.

Frazier, M., 2016. Hives for Hire: Are You Getting Your Money's Worth? PennState Extension. Available at: https://extension.psu.edu/hives-for-hire-are-you-getting-your-moneys-worth [Accessed January 3, 2021].

Free, J.B., 1993. Insect pollination of crops. London: Academic Press.

Geslin, B., Aizen, M.A., Garcia, N., Pereira, A.-J., Vaissière, B.E., \& Garibaldi, L.A., 2017. The impact of honey bee colony quality on crop yield and farmers' profit in apples and pears. Agriculture, Ecosystems \& Environment, 248, pp.153-161. DOI: 10.1016/j.agee.2017.07.035.

Gibbs, J., Elle, E., Bobiwash, K., Haapalainen, T., \& Isaacs, R., 2016. Contrasting pollinators and pollination in native and non-native regions of highbush blueberry production. Plos One, 11(7), p.e0158937. DOI: 10.1371/journal.pone.0158937

Girard, M., Chagnon, M. \& Fournier, V., 2012. Pollen diversity collected by honey bees in the vicinity of Vaccinium spp. crops and its importance for colony. Botany, 90(7), pp.545555. DOI: $10.1139 / \mathrm{b} 2012-049$

Goodrich, B.K. \& Goodhue, R.E., 2020. Are all colonies created equal? The role of honey bee colony strength in almond pollination contracts. Ecological Economics, 177, p.106744. DOI: $10.1016 /$ j.ecolecon.2020.106744

Hoffman, G.D., Lande, C. \& Rao, S., 2018. A novel pollen transfer mechanism by honey bee foragers on highbush blueberry (Ericales: Ericaceae). Environmental Entomology, 47(6), pp.1465-1470. DOI: 10.1093/ee/nvy162

Isaacs, R. \& Kirk, A.K., 2010. Pollination services provided to small and large highbush blueberry fields by wild and managed bees. Journal of Applied Ecology, 47(4), pp.841849. DOI: $10.1111 / \mathrm{j} .1365-2664.2010 .01823 . x$

Javorek, S.K., Mackenzie, K.E. \& Kloet, S.P.V., 2002. Comparative Pollination Effectiveness Among Bees (Hymenoptera: Apoidea) on Lowbush Blueberry (Ericaceae: Vaccinium angustifolium). Acta Neophilologica, 95(3), pp.345-351. DOI: 10.1603/00138746(2002)095[0345:CPEABH]2.0.CO;2

Kloet, S.P.V., 1988. The genus Vaccinium in North America. Ottawa: Canadian Government Publishing Center.

Kulyukin, V.A., 2017. In situ omnidirectional vision-based bee counting using 1d haar wavelet spikes. Proceedings of the International MultiConference of Engineers and Computer Scientists. 1, pp. 182-187.

Lehnert, T. \& Shimanuki, H., 1980. European foulbrood disease control in honey bee colonies used for blueberry and cranberry pollination. American Bee Journal. 120(6), pp.429-430.

MacKenzie, K.E., 1997. Pollination requirements of three highbush blueberry (Vaccinium corymbosum L.) cultivars. Journal of the American Society for Horticultural Science. 122(6). DOI: 122. 10.21273/JASHS.122.6.891.

Magnier, B., Ekszterowicz, G., Laurent, J., Rival, M., \& Pfister, F., 2018. Bee hive traffic monitoring by tracking bee flight paths. In Proceedings of the 13th International Joint Conference on Computer Vision, Imaging and Computer Graphics Theory and Applications. International Conference on Computer Vision Theory and Applications. SCITEPRESS - Science and Technology Publications, 5, pp. 563-571. DOI: $10.5220 / 0006628205630571$

Martin, K., Anderson, B., Minnaar, C., \& de Jager, M., 2019. Honey bees, Apis mellifera, are 
547

548

549

550

551

552

553

554

555

556

557

558

559

560

561

562

563

564

565

566

567

568

569

570

571

572

573

574

575

576

577

578

579

580

581

582

583

584

585

586

587

588

589

590

important pollinators of the highbush blueberry variety Ventura despite the inability to sonicate. BioRxiv. 551523. DOI: 10.1101/551523

Mayer, D.F. \& Burgett, M., 1993. Honey Bees. WSU Tree Fruit | Washington State University. Available at: http://treefruit.wsu.edu/orchard-management/pollination/honey-bees/ [Accessed January 3, 2021].

McGregor, S.E., 1976. Insect pollination of cultivated crop plants. Washington: Agricultural Research Service, U.S. Dept. of Agriculture.

Nasr, M.E., Thorp, R.W., Tyler, T.L., \& Briggs, D.L., 1990. Estimating honey bee (Hymenoptera: Apidae) colony strength by a simple method: measuring cluster size. Journal of Economic Entomology, 83(3), pp.748-754. DOI: 10.1093/jee/83.3.748

NJ Commercial Vegetable Production Recommendations, 2015. Assessment of Honeybee Colony Size \& Strength. Vegetable Crops Online Resources. Available at: https://njvegetable-crops-online-resources.rutgers.edu/2015/04/assessment-of-honeybee-colonysize-strength/ [Accessed January 3, 2021].

OAR, 2020. Bees and Oregon standards of bee colony strength for colonies used in commercial pollination of crops. 63-055. Available at:

https://secure.sos.state.or.us/oard/displayDivisionRules.action?selectedDivision=2732 [Accessed January 3, 2021].

Reka, S.K., 2016. A Vision-Based Bee Counting Algorithm for Electronic Monitoring of Langsthroth Beehives. All Graduate Theses and Dissertations, 4960.

Rollin, O. \& Garibaldi, L. A. (2019). Impacts of honeybee density on crop yield: A metaanalysis. Journal of Applied Ecology, 56(5), 1152-1163. doi: 10.1111/1365-2664.13355

Sagili, R.R. \& Burgett, D.M., 2011. Evaluating Honey Bee Colonies for Pollination: A Guide for Commercial Growers and Beekeepers. Pacific Northwest Extension, 623.

Sagili, R.R. \& Caron, D., 2017. Insights into honey bee pollination in the Pacific Northwest. American Bee Journal, 153, pp. 973-976.

Spivak, M. \& Reuter, G.S., 2001. Resistance to American foulbrood disease by honey bee colonies Apis mellifera bred for hygienic behavior. Apidologie, 32(6), pp.555-565. DOI: 10.1051/apido:2001103

Tuell, J.K. \& Isaacs, R., 2010. Weather During Bloom Affects Pollination and Yield of Highbush Blueberry. Journal of Economic Entomology, 103(3), pp.557-562. DOI: 10.1603/EC09387

USDA NASS, 2019. 2019 Blueberry Statistics. Available at: https://www.nass.usda.gov/Statistics_by_State/New_Jersey/Publications/Blueberry_Stati stics/NJ\%202019\%20Blueberry\%20Summary.pdf [Āccessed January 2, 2021].

USDA NASS, 2020. Noncitrus Fruits and Nuts 2019 Summary. ISSN: 1948 - 2698, pp.27-28. Available at: https://downloads.usda.library.cornell.edu/usdaesmis/files/zs25x846c/0g3551329/qj72pt50f/ncit0520.pdf [Accessed January 2, 2021].

Waite, R.J., Brown, M.A., Thompson, H.M., \& Bew, M.H., 2003. Controlling European foulbrood with the shook swarm method and oxytetracycline in the UK. Apidologie, 34(6), pp.569-575. DOI: 10.1051/apido:2003052

Wardell, G.I., 1983. European Foulbrood: Association with Michigan Blueberry Pollination and Control. Ph.D. Thesis. East Lansing: Michigan State University.

Wood, S.C., Chalifour, J.C., Kozii, I.V., Medici de Mattos, I., Klein, C.D., Zabrodski, M.W.,

Peer] reviewing PDF | (2021:02:57974:1:1:NEW 20 Apr 2021) 
591 Moshynskyy, I., Guarna, M.M., Wolf Veiga, P., Epp, T., \& Simko, E., 2020. In vitro effects of pesticides on European foulbrood in honeybee larvae. Insects, 11(4). p.252. DOI: $10.3390 /$ insects11040252 


\section{Figure 1}

Figure 1. Average colony strength before and after pollination.

A comparison of average colony strength (measured in frames of adult bees) at four different commercials farms before and after pollination. The horizontal line in each box signifies the median field strength for all farms, boundaries exist at the 25th and 75th percentiles, and whiskers extend to the most extreme data point that is no more than 1.5 times the length of the box. Data were collected in northwest Oregon in 2019. 


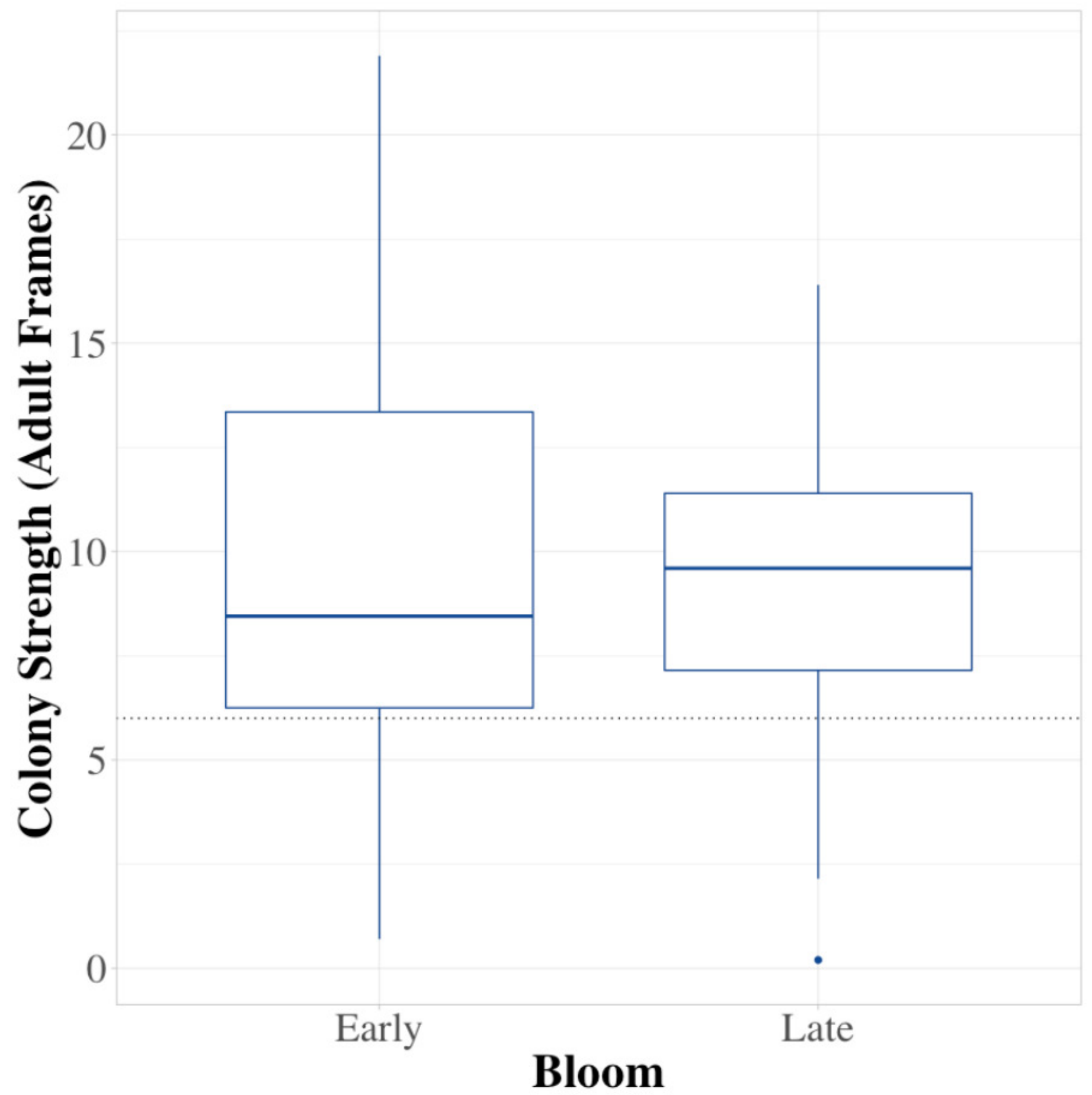




\section{Figure 2}

Figure 2. EFB severity before and after pollination.

The relative severity rating (0-3) of European foulbrood (EFB) found in individual colonies located at four blueberry fields, as colonies enter (Early) and leave (Late) pollination in (a) 2019 and (b) 2020. A rating of 0 indicated that no EFB was detected at the colony, and a rating of 3 was the most severe case a colony could be assigned (see text for description). Dots indicate the rating assigned to an individual colony at the time of the assessment. One farm from 2019 was no longer available in the 2020 assessment, but the other three remain consistent across the two years. Data were collected in northwest Oregon. 


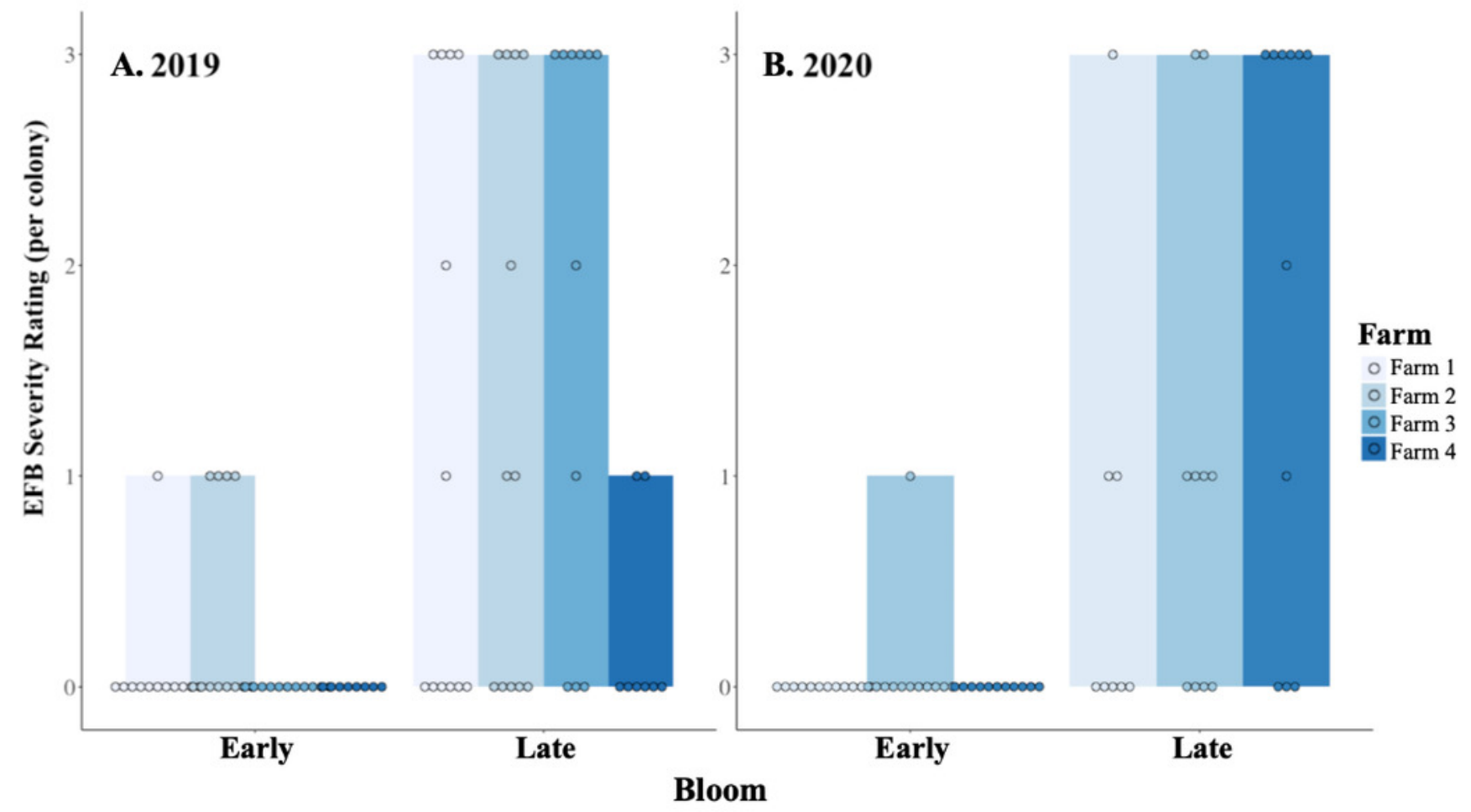




\section{Figure 3}

Figure 3. Comparison of colony strength assessments.

Correlations among the adult and brood population (Liebefeld method) and two labor-saving assessment methods, cluster counts (cluster) and returning flight counts (flight) (see text for description, $n=49$ colonies). Correlation coefficients (Kendall's tau) are listed in the lower cells and designated in strength by color as indicated by the scale. Ellipses indicate: (1) correlations with P-value $<0.05$ (i.e., cells without an ellipse are $\geq 0.05$ ) and (2) the color and eccentricity of the ellipse, which is scaled to the correlation value according to Friendly (2002). 


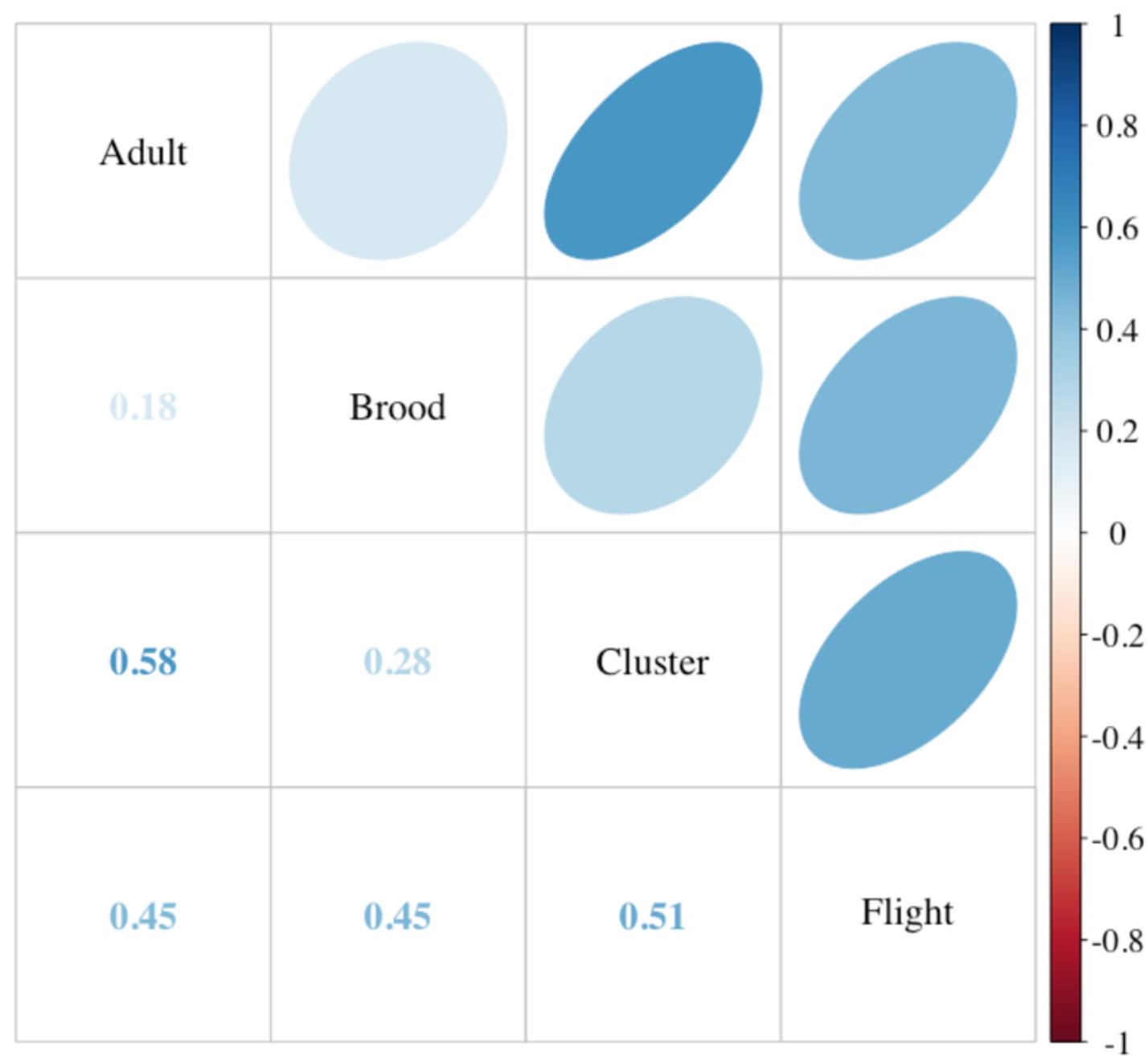




\section{Figure 4}

Figure 4. Colony strength linear model.

The relationship between the frames of adult bees in a colony to the rate of returning foragers at its entrance ( $n=84$ colonies). Each dot represents a colony, and the color of the dots indicates the temperature at which the returning flight data were recorded. Our linear model prediction for the number of frames of adult bees (frames) depends on the number of ' $x$ ' returning bees to the colony $\left(R^{2}=0.32, P<0.0001\right)$. The trendline approximates that for every thirteen returning bees, the internal frame count of adult bees is predicted to increase by one, with a $95 \%$ confidence interval. The horizontal dotted line indicates the 6 minimum recommended frames of adult bees for adequate pollination as recommended by Sagili and Burgett (2011).

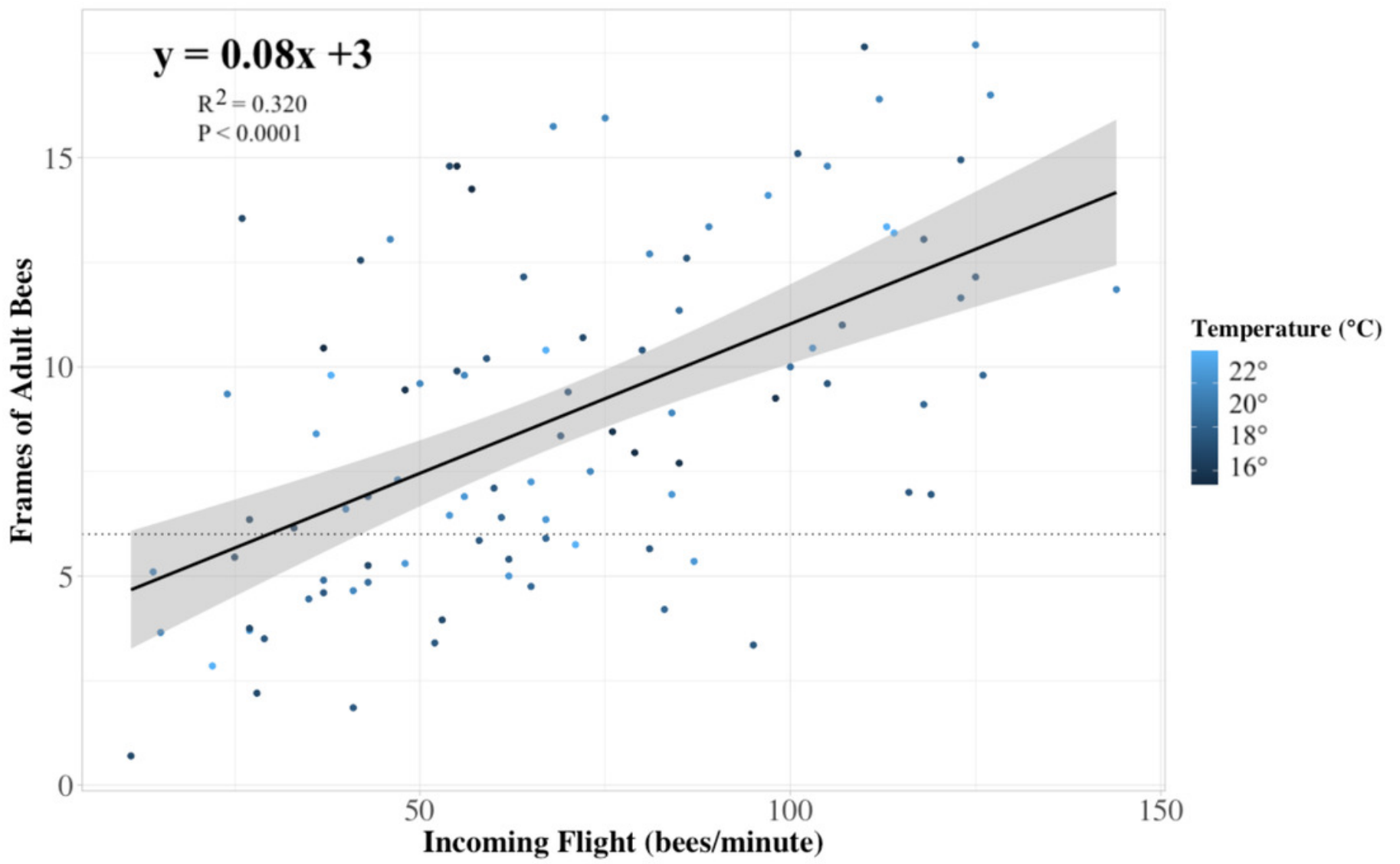




\section{Figure 5}

Figure 5. Comparisons among fields and estimated yield.

Correlations among various field components in (a) 2019 ( $n=12$ fields) and (b) 2020 ( $n=13$ fields). From top to bottom: honey bee flower visitation, bumble bee flower visitation, flight of returning foragers at colony entrance, percentage of blueberry fruit set, number of flowers per field, average berry weight in $\mathrm{kg}$, and yield approximation in $\mathrm{kg} / \mathrm{ha}$. Positive correlation coefficients (Kendall's tau) are displayed in blue and negative correlations in red as indicated by the legend of the right. Ellipses indicate: (1) correlations with p-value $<0.05$ (i.e., cells without an ellipse are 20.05 ) and (2) the color and eccentricity of the ellipse, which is scaled to the correlation value according to Friendly (2002).
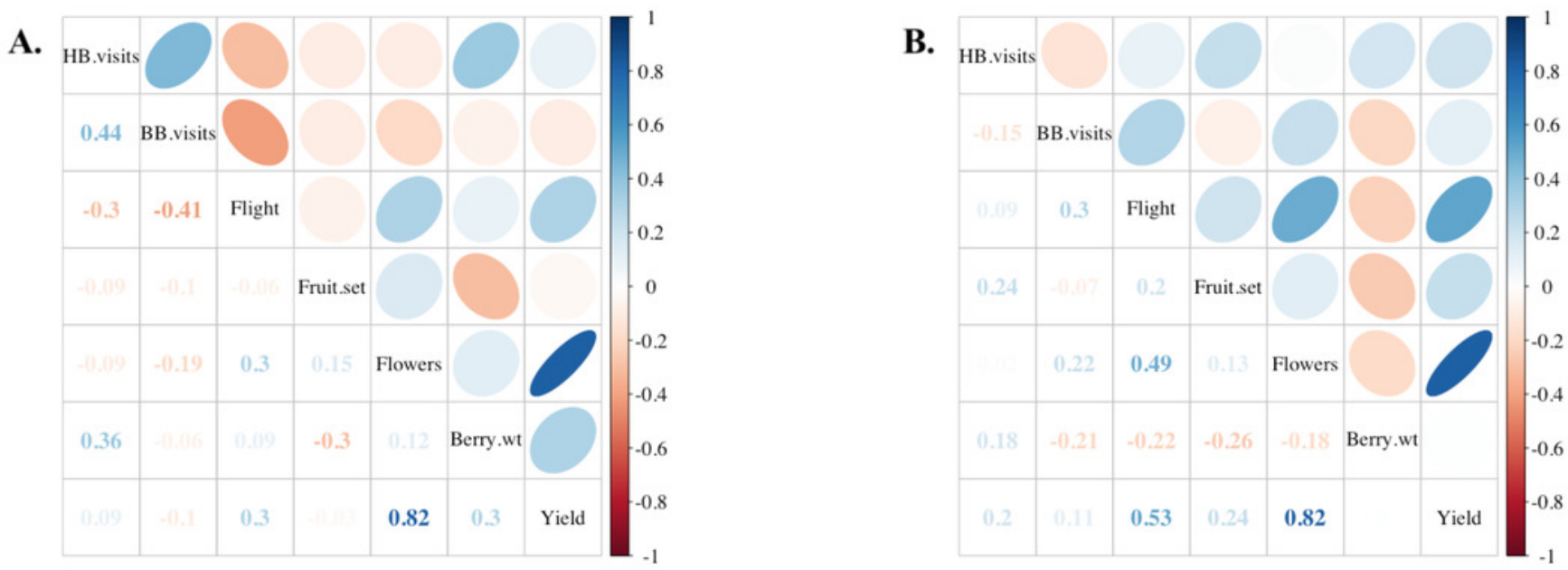


\section{Figure 6}

Figure 6. Colony strength as a predictor of yield linear model.

The relationship between the estimated field-level blueberry yield in relation to a predictor of average field colony strength, namely the average rate of returning foragers to colonies in the same field ( $\mathrm{n}=25$ fields, 2019 and 2020 data combined). Each symbol represents a field, and the shape and color of the symbol indicate the variety planted at each field. Our linear model prediction for estimated blueberry yield (yield estimate) again depends on the number of ' $x$ ' returning bees to the colony $\left(R^{2}=0.421, P=0.0008\right)$. The trendline approximates that for every 23 returning bees, the estimated yield is predicted to increase by $10,000 \mathrm{~kg} / \mathrm{ha}$, with a $95 \%$ confidence interval. The vertical line indicates the 6 minimum recommended frames of adult bees for adequate pollination as recommended by Sagili and Burgett (2011) translated into 38 bees per minute using the equation provided in Fig. 4 .

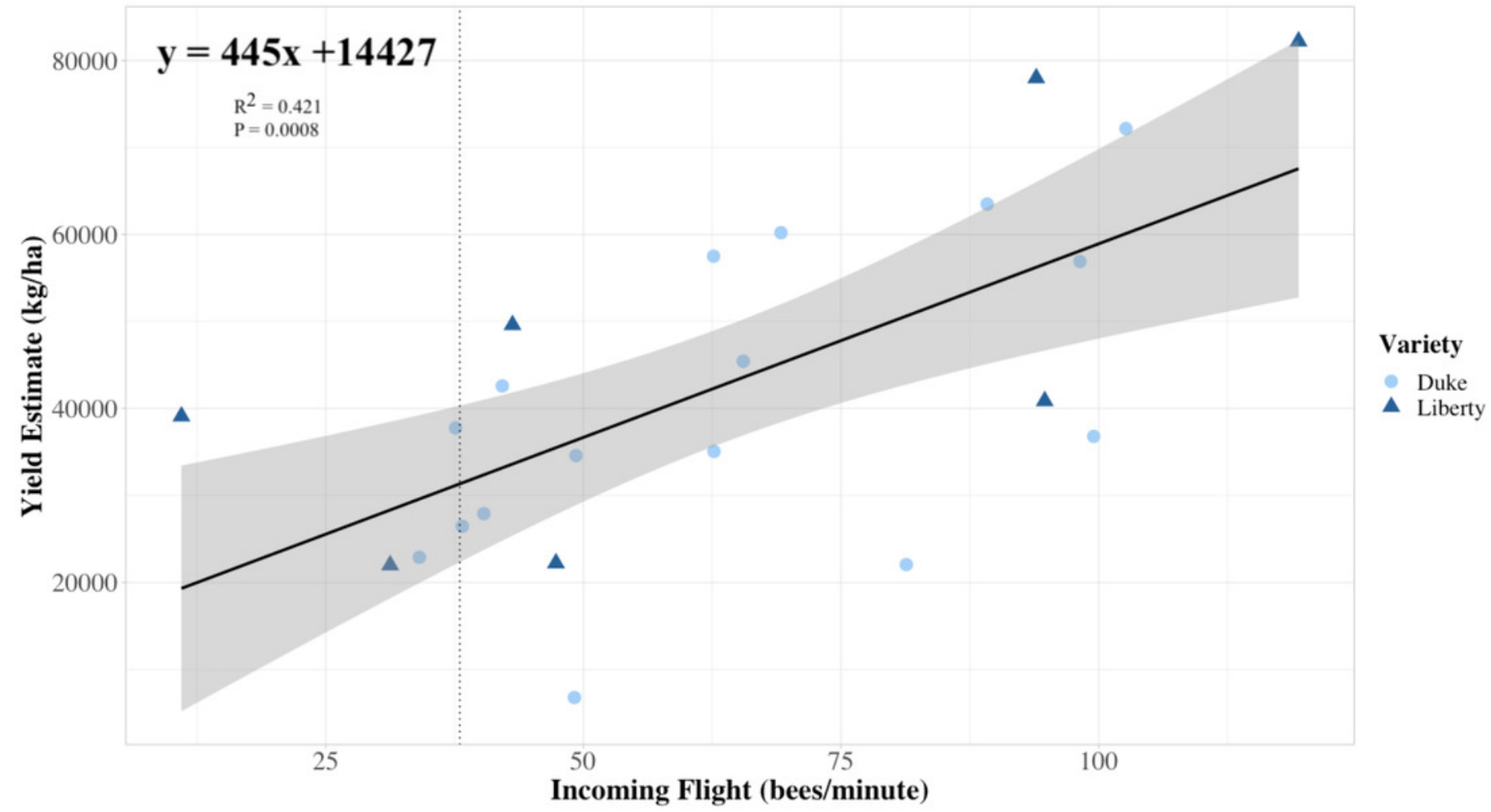

